\title{
EFFECT OF INHIBITORS ON CHLORIDE-DEPENDENT TRANSMURAL POTENTIAL IN THE RECTAL WALL OF SCHISTOCERCA GREGARIA
}

\author{
L. Herrera, R. Jordana, and F. Ponz \\ Department of Loology and Department of Physiology. \\ University of Navarra, Pamplona, Spain
}

(Keceived 30 November 19761

\begin{abstract}
Previous experiments in vitro revealed a transmural potential difference (PD) and a shortcircuit current (Isc) across the rectal wall of Schistocerca gregaria, which were dependent on chloride ions in lumen. The present report shows that anoxia, dinitrophenol and cyanide inhibit DP and Isc, proving that the required energy derives from oxidative metabolism. Acetazolamide also inhibits DP and Isc. Ouabain, when in haemocoele, has also an inhibitory effect, not ascribable to a $\mathrm{Na}^{+}-\mathrm{K}^{+}$ pump blocking action. It is suggested that $\mathrm{HCO}_{3}^{-}$plays an important rôle in the active transport of $\mathrm{Cl}^{-}$from lumen to haemocoele and that oubain may in some way inhibit chloride pumping.
\end{abstract}

\section{INTRODUCTION}

THE: IMPORTANCE of the rectal wall in insects as a regulator system of body fluids has been shown in many studies (Shaw and Stobbart, 1970; Phillips, 1964a, b; Stobbart, 1969). The primary excretion produced in the Malpighian tubules concentrates in the posterior part of the intestine through an ions and water resorption.

A transmural potential difference (PD) of approximately $35 \mathrm{mV}$ and a short-circuit current (Isc) of approximately $300 \mu \mathrm{A} \mathrm{cm}^{-2} \mathrm{~h}^{-1}$ have been measured in vitro in the rectum of Schistocerca gregaria (HERRERA, 1975: HERrERA et al., 1976). They were interpreted as the result of a net chloride transport from lumen to haemocoele, suggesting the possible existence of a chloride pump in the luminal membrane, which would transport this anion from lumen to haemolymph. and another $\mathrm{Na}^{+}-\mathrm{K}^{+}$pump in the haemocoele membrane that would expel $\mathrm{Na}^{+}$from the epithelial cells, accepting $\mathrm{K}^{+}$.

As active transport mechanisms require an energy source, they are subjected to inhibitions from various substances. like DNP and cyanide, and from anaerobiosis. Since transport depends on the presence of specific enzymes (GLYNN, 1964) they in turn can be susceptible to other inhibitors such as cardiac glycosides, acetazolamide, sulfonamides, etc. Haskell et al. (1965) observed in the isolated middle intestine from Hyalophora cecropia larvae, an inhibition of the Isc in anaerobiosis as well as in the presence of dinitrophenol on the haemocoelic compartment. Ouabain did not produce such effects.

IRviNe and PHILLIPS (1971) found that rectal water transport in $S$. gregaria. is totally inhibited by a mixture of potassium cyanide $(\mathrm{KCN})$ and iodoacetate
(IAA) $10^{2} \mathbf{M}$; this effect was explained as a sodium absorption inhibition and a chloride ion movement increase towards lumen. A 10-times lower concentration of the inhibitors diminished $\mathrm{Na}$ transport. but not that of water. HERRERA et al. (1976) proposed that the rectal wall potential is primarily dependent on chloride transport, responsible in turn for $\mathrm{Na}^{+}$, $\mathrm{K}^{+}$, and $\mathrm{H}_{2} \mathrm{O}$ flux.

The effect of different inhibitors on PD and Isc has been studied in the present work, in order to clarify the $\mathrm{Cl}^{-}$pump function and its dependence on cellular metabolism.

\section{MATERIALS AND METHODS}

Adult male and female specimens of the desert locust (Schistocerca gregaria) were used for the in vitro experiments. The way to obtain the everted rectal preparations, the procedure for measuring PD and Isc, as well as the composition of standard solution were described in a former paper (HerRfra et al. 1976). Conditions for anaerobiosis were obtained by bubbling $\mathrm{N}_{2}$ through the preparation instead of $\mathrm{O}_{2}$.

The effects of potassium cyanide, 2.4-dinitrophenol (DNP), acetazolamide, and ouabain added to the medium were tested.

After a control incubation period of the preparations in the standard medium during approximately $13 \mathrm{~min}$ the PD and the Isc were measured. The medium was immediately changed using another one with the inhibitor, either in the lumen or in the haemocoele side, and the PD and the Isc were again measured. The standard medium was restored after $10 \mathrm{~min}$ and the variations produced in PD and Isc were once more registered 


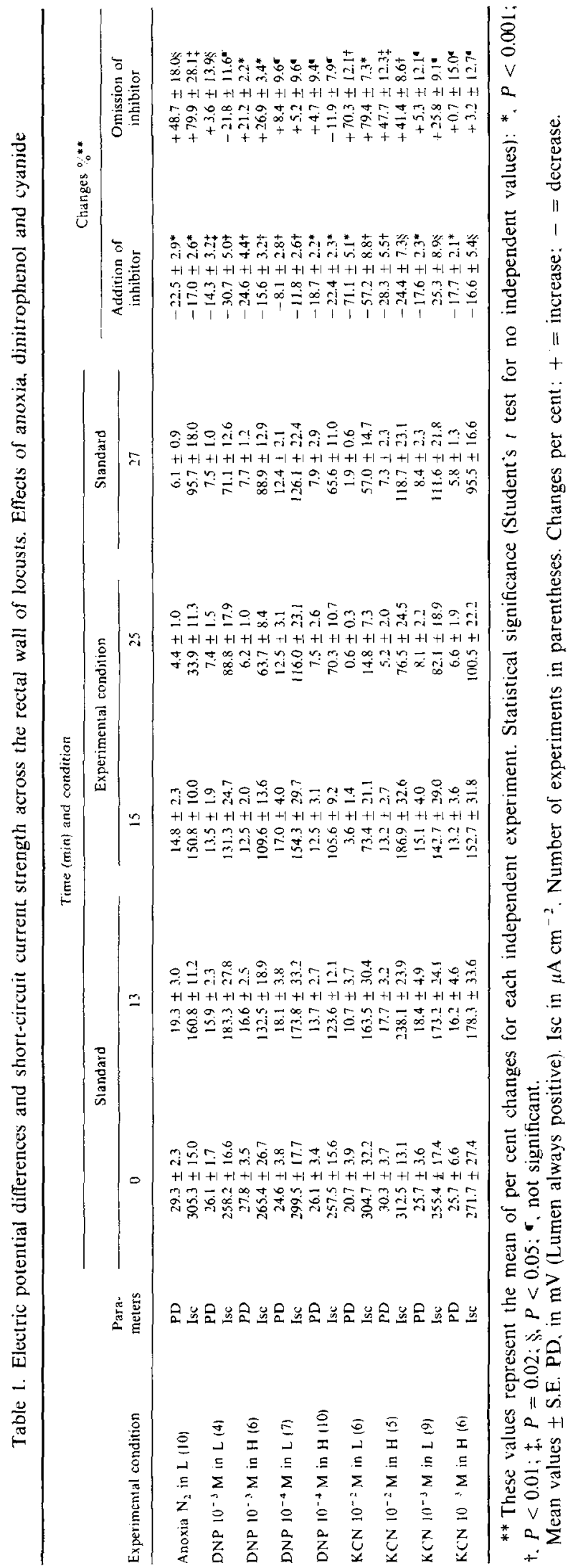




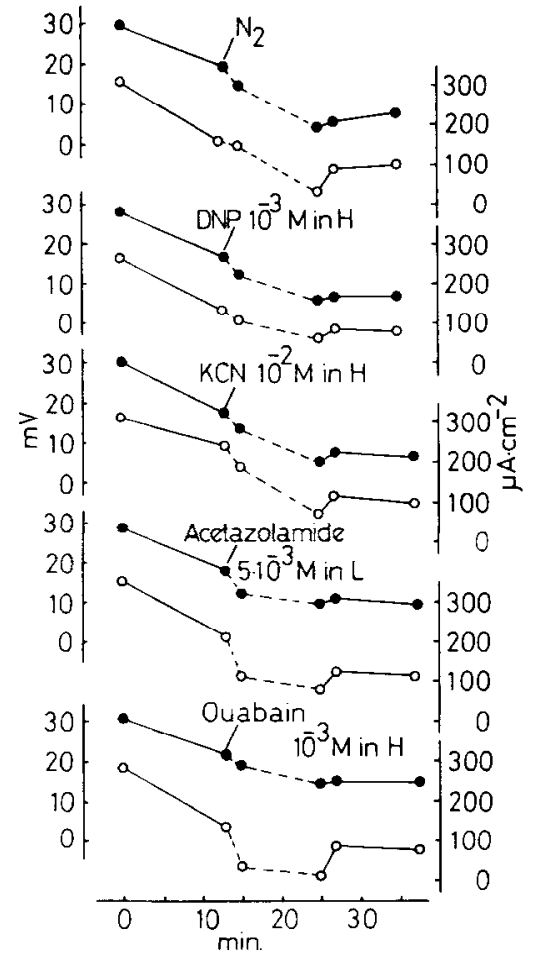

Fig. 1. Electropotential difference (PD) and short-circuit current (Isc) across the rectal wall of locust. Effects of anoxia $\left(\mathrm{N}_{2}\right)$. DNP. KCN. acetazolamide and ouabain on the lumen (L) or haemocoel (H). PD (O). Isc (O). Control, -.-. : Inhibitor. -..-.

\section{RESULTS}

The statistical analysis of the observed changes in PD and Isc present, in most cases, a high significance. In the few cases which do not show enough statistical significance. changes have been considered valid only when the shifts were in the same direction in $100 \%$ of the experiments, in spite of individual quantitative differences. It should also be mentioned that the purpose of this paper was to verify whether PD and Isc were or not affected by the inhibitors tested. These differences may be due to small technical variations, such as the insulation degree in the saline bridges employed, handling of preparations, etc.

\section{Anacrobiosis}

The PD and the Isc declined after $\mathrm{N}_{2}$ was substituted for $\mathrm{O}_{2}$ in the gasification of the rectal wall preparations. Twelve minutes after the suppression of $\mathrm{O}_{2}$, i.e. $25 \mathrm{~min}$ from the initiation of the experiment (Table 1, Fig. 1), both PD and Isc diminished considerably. A clear recovery of both parameters was observed when $\mathrm{O}_{2}$ was restored to the medium. The total blocking of PD and Isc was not obtained, perhaps because of the presence of some $\mathrm{O}_{2}$, since the bubbling takes place only in lumen and there might be an $\mathrm{O}_{2}$ exchange at the free surfaces.

\section{2,4-Dinitrophenol}

This inhibitor, a well known uncoupler of oxidative phosphorylation. has been used at $10^{-+} \mathrm{M}$ and $10^{-3} \mathrm{M}$ concentrations. either in lumen or in haemocoele (Table 1, Fig. 1). A $10^{-4} \mathrm{M}$ concentration in haemocoele produced a small Isc inhibition, without an appreciable $\mathrm{PD}$ change, but a $10^{-3} \mathrm{M}$ concentration exerts a highly significant inhibitory effect on both PD and Isc. followed by their recovery upon the suppression of DNP. This latter concentration in lumen produced only a small Isc decline. An easier penetration of DNP through the haemocoelic membrane might account for this difference of effect. DNP inhibitions were inferior to those produced in the absence of $\mathrm{O}_{2}$.

The required DNP concentrations to produce inhibitions were higher than those usually employed for the uncoupling of oxidative phosphorylation.

\section{Cyanide}

A $10^{-2} \mathrm{M}$ concentration of potassium cyanide in lumen produced after 2 min a strong PD and Isc inhibition, 71 and $57^{\circ}{ }_{0}$, respectively, and it practically nullified them after $10 \mathrm{~min}$. After removing the $\mathrm{KCN}$ through washing and restoring the standard medium, both parameters recovered quickly (Table 1, Fig. 1). The same concentration in the haemocoele caused a similar effect, but less intense, perhaps because of a lower KCN diffusion from this side. Lower concentrations of cyanide produced smaller inhibitions.

\section{Acetusolamide}

In mammals. acetazolamide, a well known diuretic. (SPraglle, 1958). acts als a specific inhibitor of carbonic anhydrase, reducing the $\mathrm{HCO}_{3}^{-}$intracellular concentration and. therefore, the possibility of a $\mathrm{HCO}_{3}^{-}$exchange with $\mathrm{Cl}^{-}$and the resorption of $\mathrm{H}_{2} \mathrm{O}$ in the renal tubules (ROBSON and STACEY, 1962). It has been observed that in other tissues it affects the ionic exchange across membranes (Gooding, 1975). This inhibitor has been used to observe the effect of $\mathrm{HCO}_{3}^{-}$on $\mathrm{Cl}^{-}$transport, since the $\mathrm{PD}$ and $\mathrm{Isc}$ in the rectal wall of Schistocerca gregaria is dependent on chloride.

Acetazolamide was only added in lumen (Tahle 2. Fig. 1). where the anion exchange could take place. and an inhibitory action on PD and Isc wals observed. The inhibition was of nearly the same magnitude at $10^{-3} \mathrm{M}$ than at $5 \times 10^{-3} \mathrm{M}$ concentrations.

\section{Ouabain}

Ouabain was tested either in lumen or in haemocoele. No effect of ouabain on transmural PD was found (Table 2. Fig. 1). but it exerts an inhibitory effect on the Isc, when present in haemocoele. At $10^{-3} \mathrm{M}$ concentration, ouabain produced very high inhibition and practically nullified the Isc. as if the net flux of ions from lumen to haemolymph. was stopped. 

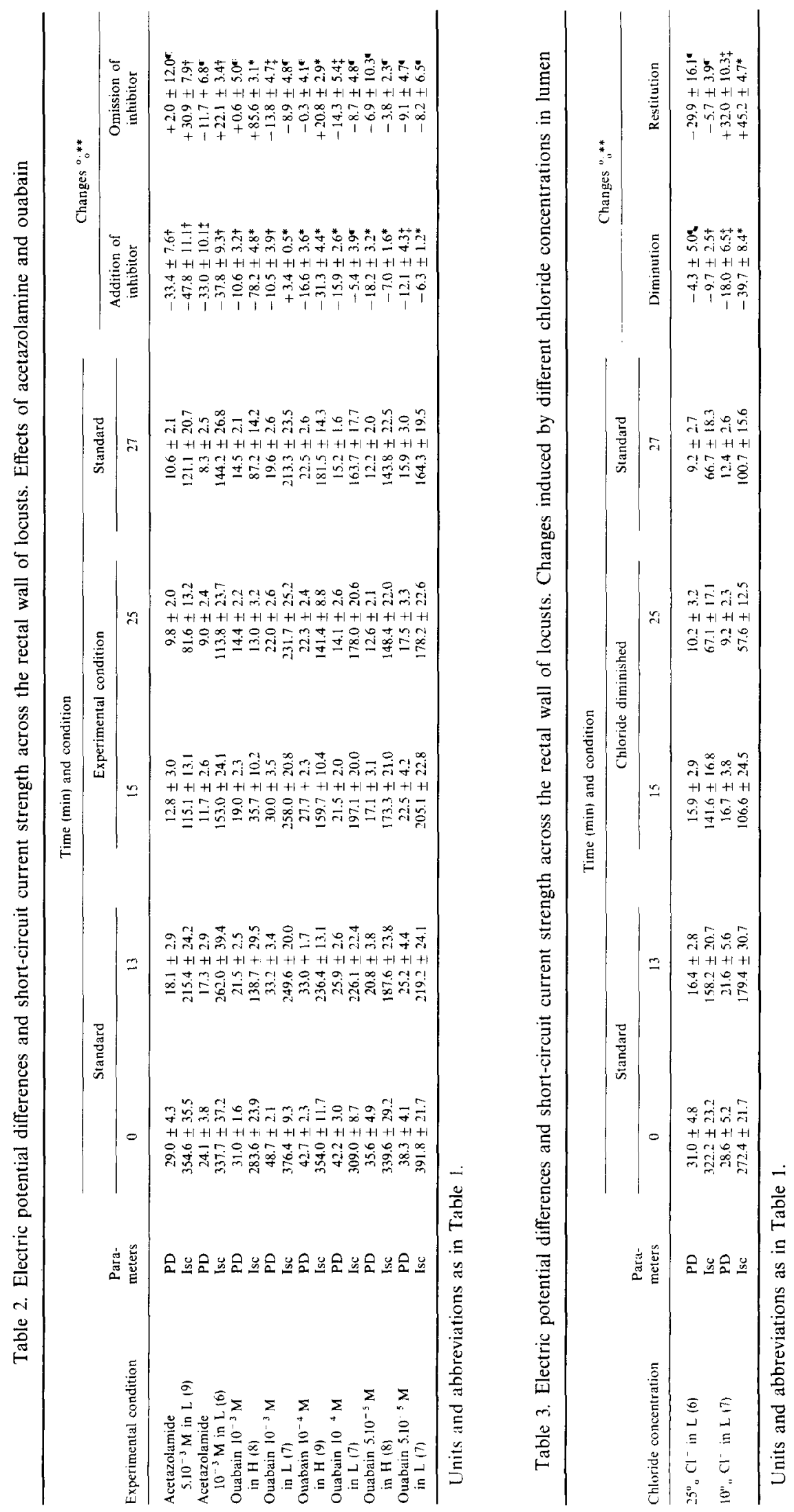


\section{DISCUSSION}

\section{Dependence of PD and ISc on aerobic metabolism}

The results show that PD and Isc in the rectal wall of S. yregaria are dependent on aerobic metabolism.

Anoxia, provoked on substituting $\mathrm{N}_{2}$ for $\mathrm{O}_{2}$, produces a decline in PD and Isc. and quickly recovered on restoring $\mathrm{O}_{2}$. A similar phenomenon was observed in the middle intestine of Hyalophora cecropia (HasKELL et al. 1965), where an Isc inhibition of $83^{\circ}$ o was found. Similar results were obtained by WoOD et al. (1969) on the transluminal potential. The impossibility of nullifying the PD and Isc might be due, either to the experimental conditions that do not guarantee total absence of $\mathrm{O}_{2}$ or to some energy production from anaerobic processes.

DNP acts similarly to anaerobiosis, but less intensely. The blocking of the ATP oxidative production does not lead to the total nullification of PD or Isc, pointing also to a certain capacity in the tissues for obtaining energy from non-aerobic processes. HASKELI it al. (1965) found a similar phenomenon in Hyalophora cecropia. IRvine and PHILlips (1971), however, observed that the $10^{-3} \mathrm{M}$ DNP in Schistocerca in titro completely abolished water transport in the rectal wall. This discrepancy might be due perhaps that their experiments were not carried out under strict aerobic condition. since the sacs were not everted and the oxygenation takes place at the haemocoelic side, rather than at the luminal surface.

A $10^{-2} \mathrm{M}$ concentration of $\mathrm{KCN}$, which produced an aerobic metabolism inhibition, completely nullified the PD and Isc. Ten times lower concentrations produced a lesser inhibition.

These results reveal that the transmural PD and the Isc, and consequently the net flux of $\mathrm{Cl}^{-}$, mainly depend on the energy derived from aerobic processes. although the possibility that the cell obtains a certain amount of energy from anaerobic metabolic processes remains open.

\section{Relation between $P D$ and $I$ sce, and $\mathrm{HCO}_{3}^{-}$}

The inhibitory effect of acetazolamide on PD and Isc in the rectum of $S$. gregaria, suggests an interesting relation between bicarbonate and the net flux of $\mathrm{Cl}^{-}$. As acctazolamide inhibits carbonic anhydrase. (EI)Wards and PAtTon. 1967), it will lessen $\mathrm{HCO}_{3}^{-}$ concentration in the cells. The net movement of $\mathrm{Cl}^{-}$ from lumen to haemocoele might be dependent on the level of intracellular $\mathrm{HCO}_{3}^{-}$. due perhaps to an exchange of $\mathrm{Cl}^{-}$and $\mathrm{HCO}_{3}^{-}$at the luminal membrane. This exchange. however, would not be sufficient to explain the net flux of $\mathrm{Cl}^{-}$to haemocoele since it takes place against a high electrochemical gradient. Moreover, if the net flux of $\mathrm{Cl}^{-}$were a simple consequence of $\mathrm{HCO}_{3}^{-}$outflux towards lumen, then the partial substitution of $\mathrm{Cl}^{-}$by the nonpenetrating $\mathrm{SO}_{4}^{-}$anion a gradual effect on the potential should be expected, but this does not occur. In fact. $\mathrm{Cl}^{-}$ concentration in the luminal side can be considerably lessened without altering the PD or the Isc. Both parameters begin to decrease only with $\mathrm{Cl}^{-}$concentrations as low as $18 \mathrm{mEq} / 1$ (Table 3). Such a behaviour conforms better with a $\mathrm{Cl}^{-}$active transport system with high affinity for this anion.

Another possibility would be that the systems for active transport of chloride were sensitive to bicarbonate ions.

\section{Effect of ouahain}

Ouabain. a $\mathrm{Na}^{-} \cdot \mathrm{K}^{+}$-dependent ATP-ase specific inhibitor. abolishes the activity of the $\mathrm{Na}^{+}$and $\mathrm{K}^{+}$ pump.

Ouabain lessens mainly the Isc (flux of anions) in the rectal wall of the Schistocerca, only when the glucoside is in haemocoele at a $10^{-4} \mathrm{M}$ or higher concentration. This effect cannot be attributed to an inhibition of the $\mathrm{Na}^{+}$-pump, which on the contrary would provoke an increase in Isc and in haemocoele negativity, as it happens by omitting $\mathrm{Na}^{+}$and $\mathrm{K}^{-}$ in the medium (Herrera et al. 1976). It has to be admitted, therefore, that the $\mathrm{Cl}^{-}$active transport mechanism itself is sensitive to ouabain and that it is likely located at the basal side of the epithelial cells, since the inhibitor acts only from haemocoele.

The lesser sensitivity of PD to ouabain is not surprising. since a small flux of anions is sufficient to maintain the potential. and ouabain does not totally inhibit $\mathrm{Cl}^{-}$transport. Furthermore the simultaneous inhibition of the $\mathrm{Na}^{+}$pump may account for the lesser quantity of negative charge transferred to hacmocoele.

After a consideration of these results, the scheme suggested by HrRRERA 't al. (1976) to interpret the origin of PD and Isc in the rectal wall of $S$. greyuria remains valid, and can be expanded in the following points: (1) The PD and the Isc. directly dependent on the $\mathrm{Cl}^{-}$active transport from lumen to haemocoele, require acrobic metabolism which appears as the main energy source for transport. (2) The PD and Isc inhibitions caused by acetazolamide manifest the importance of $\mathrm{HCO}_{3}$ in the process, either, because it directly stimulates $\mathrm{Cl}^{-}$pumping. or. because it aids $\mathrm{Cl}^{-}$entrance in the cells through an exchangs: with the outflux of $\mathrm{HCO}_{3}^{-}$. (3) It is very probable that ouabain. besides inhibiting the $\mathrm{Nal}^{+}$pump. might also inhibit $\mathrm{Cl}^{-}$pumping. and if so, this transport system would be located in the basal membrane of the epithelial cells. rather than in the lumen.

Acknowledgement--This work was supported by grants from the Spanish "Ministerio de Educacion y Ciencia".

\section{REFERENCES}

EDWARIJs L. I. and PatTon R. L. (1967) Carbonic anhydrase in the house cricket Acheta domesticus. J. Insect Physiol. 13. 1333-1341.

GlynN I. M. (1964) The action of cardiac glycosides on ion movements. Pharmac. Rer. 16. 381407. 
GoODING R. H. (1975) Inhibition of diuresis in the tsetse fly (Glossina morsitans) by ouabain and acetazolamide. Experientia 31, 938-939.

Haskell J. A., Clemons R. D., and Harvey W. R. (1965) Active transport by the cecropia midgut- $\mathbf{I}$. Inhibitors. stimulants and $\mathrm{K}^{+}$transport. J. cell. comp. Physiol. 65, $45-56$.

Herrera L. (1975) Sci. D. Thesis, Navarra University.

Herrera L., Jordana R., and Ponz F. (1976) Chloridedependent transmural potential in the rectal wall of Schistocerca gregaria. J. Insect Physiol. 22. 291-297.

IrVINe H. B. and Phillips J. E. (1971) Effect of respiratory inhibition and ouabain on water transport by isolated locust rectum. J. Insect Physiol. 17, 381-383.

Phillips J. E. (1964a) Rectal absorption in the desert locust. Schistocerca gregaria Forsk.-I. Water. J. exp. Biol. 41. 15-38.
Phillips J. E. (1964b) Rectal absorption in the desert locust, Schistocerca yregaria Forsk.-II. Sodium, potassium and chloride. J. exp. Biol. 41, 39-67.

Robson J. M. and Stacey R. C. (1962) Recent Advances in Pharmacology. 3rd ed., Churchill. London.

Shaw J. and Stobbart R. H. (1970) Osmotic and ionic regulation in insects. Adr. Insect Physiol. 1, 315-399.

Spragule J. M. (1958) The chemistry of diuretics. Ann. N.Y. Acad. Sci. 71. 328-343.

STOBBART R. H. (1968) Ion movements and water transport in the rectum of the locust Schistocerca gregaria. J. Ins'ct Phvsiol. 14. 269275.

Wood J. L., Farrand P. S., and Harvey W. R. (1969) Active transport of potassium by the cecropia mid-gut -VI. Microelectrode potential profile. J. exp. Biol. $\mathbf{5 0}$, 169-178. 